\title{
Sistem Pendukung Keputusan Pembelian Mobil Baru Dengan Menggunakan Metode Multi Attribute Utility Theory (Maut)
}

\author{
Dhea Safitri ${ }^{1}$, Hairil Kurniadi Siradjudin ${ }^{2}$, Rosihan $^{3}$ \\ Program Studi Teknik Informatika, Fakultas Teknik, \\ Universitas Khairun, Jl. Jati Metro, Kota Ternate Selatan \\ dheasafitry34@gmail.com
}

\begin{abstract}
Abstrak
Mobil adalah salah satu alat transportasi darat yang penting pada saat sekarang ini. Memiliki mobil bagi sebagian besar kalangan masyarakat pada saat ini bagaikan suatu hal yang pokok dimana dapat membantu mereka dalam beraktivitas khususnya dalam bekerja.Sistem Pendukung Keputusan membantu mengambil keputusan memanfaatkan data dan model keputusan untuk menyelesaikan masalah-masalah yang tidak terstruktur dan semi terstruktur. SPK dirancang untuk menunjang keseluruhan tahapan pembuatan keputusan, yang dimulai dari tahapan identifikasi masalah. Penelitian ini bertujuan untuk membangun sebuah sistem pendukung keputusan dengan menggunkan metode Multi Attribute Utility Theory (Maut), dan dapat memberi manfaat bagi calon pembeli mobil baru. Metode Maut merupakan suatu skema yang evaluasi akhir, $\mathrm{v}(\mathrm{x})$ dari suatu objek $\mathrm{x}$ didefinisikan sebagai bobot yang dijumlahkan dengan suatu nilai yang relevan terhadap nilai dimensinya. Kelebihan dari metode ini adalah dapat mengetahui dengan cepat tentang status akhir atau hasil. Penerapan metode ini mampu memberikan hasil rekomendasi sesuai dengan kriteria yang diinginkan.
\end{abstract}

Kata Kunci: Mobil, Sistem Pendukung Keputusan, Multi Attribute Utility Theory (Maut).

\section{Abstract}

Cars are one of the essential means of land transportation today. Having a car for most of the community is like a thing that can help them in their activities, especially at work. Decision Support Systems help make decisions using data and decision models to solve unstructured and semi-structured problems. DSS is designed to support all stages of decision-making, starting from the problem identification stage. This study aims to build a decision support system using the Multi-Attribute Utility Theory (Death) method to benefit prospective new car buyers. The Death Method is a scheme in which the final evaluation, $v$ (x) of an object $x$, is defined as the weight added to a value relevant to its dimension value. The advantage of this method is that it can quickly find out about the final status or result. Moreover, the application of this method can provide recommendations according to the desired criteria.

Keywords: Cars, Decision Support Systems, Multi-Attribute Utility Theory (Death)

\section{PENDAHULUAN}

Mobil adalah salah satu alat transportasi darat yang penting pada saat sekarang ini. Memiliki mobil bagi sebagian besar kalangan masyarakat pada saat ini bagaikan suatu hal yang pokok dimana dapat membantu mereka dalam beraktivitas khususnya dalam bekerja. Oleh karena itu, para produsen mobil berlomba-lomba untuk menciptakan mobil dengan keunggulan dan kelebihan yang berbeda sehingga dipasaran jumlah mobil sangat banyak dan bervariasi. Disamping adanya beragam pilihan tersebut, para konsumen 
juga dihadapkan dengan banyaknya kriteria yang berpengaruh dalam menentukan pilihan mobil misalnya harga, warna, keamanan, kelengkapan, desain, dan lainlain.

Dalam prosesnya seringkali konsumen mengalami kebingungan untuk memilih produsen atau merk mobil apa saja yang ingin dibeli, untuk memenuhi kebutuhan dan keinginan pribadi. Dan untuk memilih produsen yang tepat yang sesuai dalam memilih mobil baru adalah harga, type, merk, dan lain-lain.Untuk mengolah semua kriteria yang ada diperlukan suatu analisa yang dapat memilih dan mengelompokkan kriteria sehingga dapat membantu konsumen dalam memilih produsen mobil yang sesuai dengan kebutuhan konsumen.

Penelitian ini sebelumnya pernah dilakukan oleh Eva Yulianti 2015 dengan juduSistem Pendukung Keputusan Pemilihan Mobil Dengan Metode Simple Multy Atrribut Rating (SMART), kelebihan dari penelitian ini yaitu membandingkan dengan berbagai aspek sedangkan kekurangan dari sistem ini yaitu hanya menggunakan dua merk mobil untuk dijadikan perbandingan. Nanang Anhari 2016 dengan judul Sistem PendukungKeputusan Pembelian Mobil Baru Dengan Menggunakan Metode Analytical Hierarchy Process (AHP), kelebihan dari penelitian ini yaitu dapat menghubungkan database dengan sourcecode pada SPK dan kekurangan dari sistem ini hanya menyeleksi kriteria sesuai kebutuhan pelanggan. Annisya Agustina Awalinah 2017 dengan judul Sistem Pendukung Keputusan Pembelian Mobil dengan Membandingkan Metode Analytic Hierachy Process dan Fuzzy Associative Memory, kelebihan membandingkan dua metode antara metode FAM dan AHP dan kekurangannya yaitu metode FAM lebih memberikan rekomendasi mobil yang sesuai dengan harapan calon pembeli mobil serta lebih mudah digunakan dibandingkan metode AHP dan kekurangannya yaitu metode AHP.

Banyak metode pengambilan keputusan yang dapat membantu permasalahan diatas.Salah satu metode tersebut adalah Multi Attribute Utility Theory (MAUT) merupakan suatu skema yang evaluasi akhir, $\mathrm{v}(\mathrm{x})$, dari suatu objek $\mathrm{x}$ didefinisikan sebagai bobot yang dijumlahkan dengan suatu nilai yang relevan terhadap nilai dimensinya. Ungkapan yang biasa digunakan untuk menyebutnya adalah nilai utilitas.

Diharapkan konsumen akan merasa terbantu dengan adanya sistem ini yang memberikan saran atau rekomendasi pembelian mobil baru sesuai dengan cara menginput kriteria pada Sistem oleh Pengguna. Sehingga pada akhir prosesnya, pengguna akan mendapatkan daftar rekomendasi pembelian mobil baru berdasarkan kriteria yang dimasukkan.

Sistem Pendukung Keputusan Pembelian Mobil Baru ini dilakukan berdasarkan 3 kriteria yaitu kriteria harga, kapasitas tangki, dan kapasitas mesin, disini juga terdapat kriteria pendukung yaitu merek mobil. Adapun kriteria-kriteria yang diambil adalah berdasarkan dari penelitian terdahulu yang sudah ada. Berdasarkan latar belakang yang telah di paparkan serta menyadari betapa pentingnya menentukan pilihan yang tepat, maka penulis membuat penelitian dengan judul "SistemPendukung Keputusan Pembelian Mobil Baru dengan Menggunakan Metode Multi Attribute Utility Theory (MAUT)".

TINJAUAN PUSTAKA Sistem Pendukung Keputusan 
Sistem pendukung keputusan merupakan suatu pendekatan (atau metodologi) untuk mendukung pengambilan keputusan. Decision Support System (DSS), menggunakan CIBIS yang fleksibel, interaktif, dan dapat diadaptasi, yang dikembangkan untuk untuk mendukung solusi untuk masalah manajemen spesifik yang tidak terstruktur.

Decision Support System (DSS) biasanya menggunakan berbagai model dan dibangun sering oleh pengguna akhir oleh suatu proses interaktif dan iteratif. la mendukung semua fase pengambilan keputusan dan dapat memasukkan suatu komponen pengetahuan.

\section{Metode Multi-Attribute Utility Theory (MAUT)}

Multi Atribute Utility Theory (MAUT) merupakan suatu skema yang evaluasi akhir, $\mathrm{v}(\mathrm{x})$ dari suatu objek $\mathrm{x}$ didefinisikan sebagai bobot yang dijumlahkan dengan suatu nilai yang relevan terhadap nilai dimensinya. Ungkapan yang biasa digunakan untuk menyebutnya adalah nilai utilitas. MAUT digunakan untuk merubah dari beberapa kepentingan kedalam nilai numerik dengan skala 0-1 dengan 0 mewakili pilihan terburukdan 1 terbaik. Hal ini memungkinkan perbandingan langsung yang beragam ukuran. Hasil akhirnya adalah urutan peringkat dari evaluasi yang menggambarkan pilihan dari para pembuat keputusan. Nilai evaluasi seluruhnya dapat didefinisikan dengan persamaan (Ramadiani, 2018). Rumus dapat dilihat pada persamaanb 2.1, 2.2 dan 2.3.

Normalisasi

$U_{(x)}=\frac{x-x i^{-}}{x i^{+}-x i^{-}}$

$V(x)$
Matriks

$=\sum_{i=1}^{n} W_{j} . X i j$
Keterangan:

$\mathrm{U}(x)=$ Normalisasi Bobot Alternatif $\mathrm{x}$

$\mathrm{x}=$ Bobot Alternatif

$x i^{-}=$Bobot terburuk (minimum) dari

kriteria ke-x

$x^{+}=$Bobot terbaik (maximum) dari

kriteria ke-x

$\mathrm{X}=$ objek / alternatif

$\mathrm{V}=$ Nilai keseluruhan dari alternatif pilihan

1 kriteria.

$\mathrm{Wj}=$ bobot prioritas subkriteria.

$\mathrm{Xij}=$ Nilai alternatif pilihan kriteria.

\section{METODE PENELITIAN}

\section{Metode Pengembangan Sistem}

Metode pengembangan sistem yang digunakan dalam penelitian ini adalah metode prototype. Prototyping merupakan salah satu metode pengembangan perangkat lunak yang banyak digunakan. Model prototype ini mampu menawarkan pendekatan yang terbaik dalam hal kepastian terhadap efisiensi algoritma, kemampuan penyesuaian diri dari sebuah sistem operasi atau bentuk-bentuk yang harus dilakukan oleh interaksi manusia dengan mesin. Prototyping adalah proses iterative dalam pengembangan sistem dimana requirement diubah ke dalam sistem yang bekerja (working system) yang secara terus menerus diperbaiki melalui kerjasama antara user dan analis.

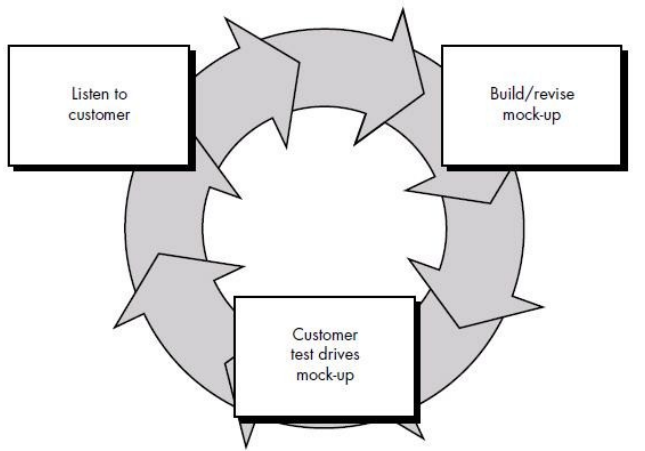

Gambar 1. Tahapan Metode Prototype 
Dari gambar 1. dapat dijelaskan sebagai berikut:

1. Yang dimaksud mendengarkan kebutuhan pembeli ialah mendengarkan kebutuhan-kebutuhan untuk memenuhi kebutuhan sistem pembelian Mobil Baru dimana tahapanini termasuk kegiatan pengumpulan data. Peneliti melakukan wawancara kepada dealer yang dituju mengenai data mobil yang dibutuhkan oleh peneliti.

2. Perancangan ialah pembuatan rancangan sistem pembelian mobil dimana tahapan ini termasuk kegiatan analisis sistem, perancangan sistem dan pembuatan program.

3. Pembeli Mencoba SPK Mobil Baru ialah konsumen mencoba sistem yang telahdibuat, jika telah memenuhi sesuai kebutuhan maka program telah final dan dapat digunakan konsumen, jika belum maka akan dilakukan evaluasi dan perbaikan program lagi.

\section{Analisa Masalah}

Masalah yang didapatkan adalah konsumen yang akan membeli mobil baru terkadang bingung dalam menentukan pilihan mobil baru mana yang terbaik yang sesuai dengan kriteria-kriteria yang di inginkan. Dengan adanya sistem ini Konsumen tidak perlu membuang-buang waktu pergi ke dealer mobil mencari mobil baru, karena pembeli dapat membeli mobil baru melalui sistem sesuai dengan kriteria yang diinginkan.

penyeleseaian metode beserta contohnya sebagai berikut: Pembelli akan memilih mobil yang diusulkan, metode yang akan digunakan untuk pembelian mobil baru yaitu metode Multi Attribute Utillity Theory (MAUT). Dibawah ini akan di Lakukan perhitungan manual dengan menggunakan metode Maut dalam menentukan pemilihan mobil baru berdasarkan nilai bobot, di mana pada perhitungan ini ada 3 data pemilihan mobil yang akan menjadi alternatif pilihan yaitu:

Input Cari Mobil:

Merek Mobil : Toyota

Transmisi : Manual

Harga $\quad: 300.000 .000$

Normalisasi Tiap Bobot

\begin{tabular}{|l|l|l|l|}
\hline Alternatif & Kategori & Spesifikasi & Harga \\
\hline $\begin{array}{l}\text { AVANZA } \\
\text { VELOZ } \\
1.5 \text { AT }\end{array}$ & 0,67 & 0,75 & 0,5 \\
\hline $\begin{array}{l}\text { AVANZA } \\
\text { VELOZ } \\
1.3 \text { MT }\end{array}$ & 0,67 & 0,5 & 0,5 \\
\hline AVANZA & 0,67 & 0,75 & 0,5 \\
VELOZ \\
1.3 AT
\end{tabular}

Rumus Normalisasi Matris Persamaan 1 $\frac{x-x i^{-}}{x i^{+}-x i^{-}}$

\begin{tabular}{|c|l|l|}
\hline \multicolumn{1}{|c|}{ Speseifikasi } & Kategori & Harga \\
\hline$\frac{0,67-0,67}{0,67-0,67}=0$ & $\frac{0,75-0,5}{0,75-0,5}=1$ & $\frac{0,5-0,5}{0,5-0,5}=0$ \\
\hline$\frac{0,67-0,67}{0,67-0,67}=0$ & $\frac{0,5-0,5}{0,75-0,5}=0$ & $\frac{0,5-0,5}{0,5-0,5}=0$ \\
\hline$\frac{0,67-0,67}{0,67-0,67}=0$ & $\frac{0,75-0,5}{0,75-0,5}=1$ & $\frac{0,5-0,5}{0,5-0,5}=0$ \\
\hline
\end{tabular}

Rumus Normalisasi Atrribute Persamaan 2 : $V(x)=\sum_{i=1}^{n} W_{j} . X i j$

Bobot $\mathrm{Wj}=[35,25,40]$

\begin{tabular}{|c|l|c|}
\hline Kategori & \multicolumn{1}{|c|}{ Spesifikasi } & Harga \\
\hline $0 \times 35=0$ & $1 \mathrm{X} 25=25$ & $0 \mathrm{X} 40=0$ \\
\hline $0 \mathrm{X} 35=0$ & $0 \mathrm{X} 25=0$ & $0 \mathrm{X} 40=0$ \\
\hline $0 \times 35=0$ & $1 \mathrm{X} 25=25$ & $0 \mathrm{X} 40=0$ \\
\hline
\end{tabular}

Hasil perangkingan diperoleh dengan nilai akhir pada $\mathrm{A} 1=25, \mathrm{~A} 2=0$, dan A3=25 maka rekomendasi yang diperoleh dengan nilai tertinggi dan terbesar ada pada A3, tapi jika nilainya sama maka akan 
dilihat dari harga yang paling murah maka alternatif $\mathrm{A} 3$ adalah alternatif yang terpilih sebagai pembelian mobil baru.

\section{Perancangan Sistem}

Pada gambar 2 dan 3 menunjukan kegiatan-kegiatan untuk menentukan pemilihan mobil.

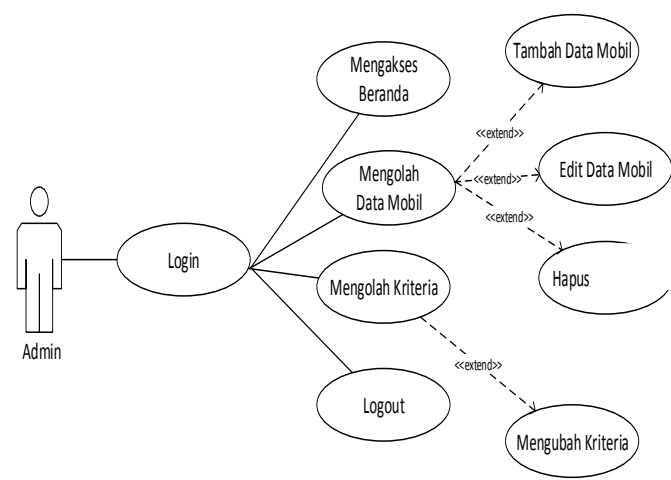

Gambar 1. Use Case Diagram

Keterangan:

1. Adminlogin ke system.

2. Admindapat mengolah halaman beranda.

3. Admin dapat mengolah data mobil.

4. Admin dapat mengolah data kriteria.

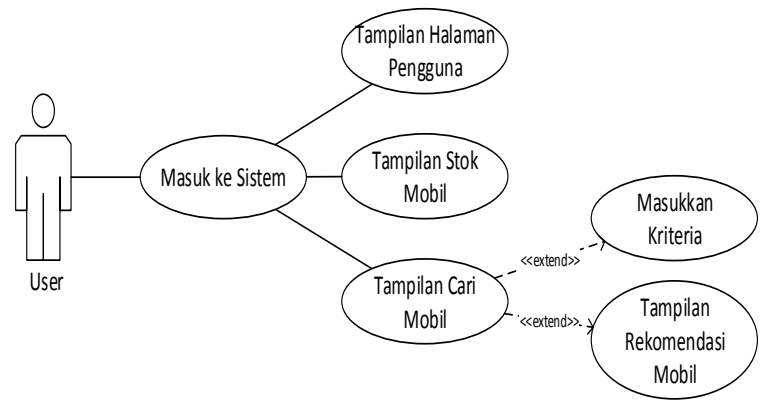

Gambar 2. Use Case User

Keterangan:

1. Penguna Masuk ke sistem.

2. Pengguna dapat melihat halaman pengguna.

3. Pengguna dapat melihat tampilan stok mobil.

4. Pengguna dapat melihat tampilan cari mobil.

5. Pengguna dapat melihat tampilan

Rekomendasi Mobil.

HASIL DAN PEMBAHASAN

Implementasi Interface
Pada halaman utama Admin terdapat 5 menu utama yaitu: data mobil, kriteria, kunjungi situs,dan logout.

BERANDA DATA MOBIL KRITERIA KUNJUNGISITUS LOGOUT Sistem Pendukung Keputusan Pembelian Mobil Baru Menggunakan Metode MAUT

Gambar 3.Beranda

\section{Pengujian Metode MAUT}

penyeleseaian metode beserta contohnya sebagai berikut: Pembelli akan memilih mobil yang diusulkan, metode yang akan digunakan untuk pembelian mobil baru yaitu metode Multi Attribute Utillity Theory (MAUT).

Tampilan Hasil Inputan

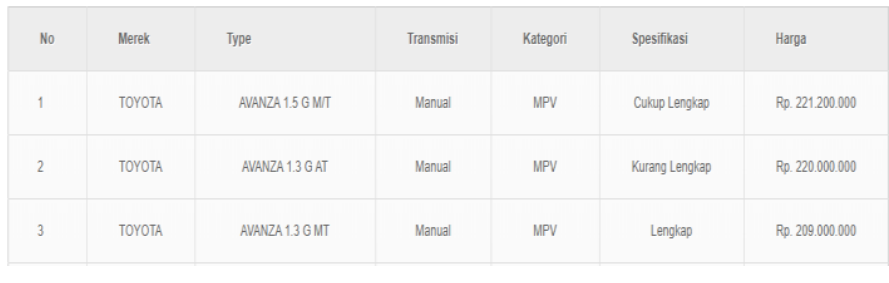

Gambar 4 Tampilan Hasil

Bobot Tiap Kriteria

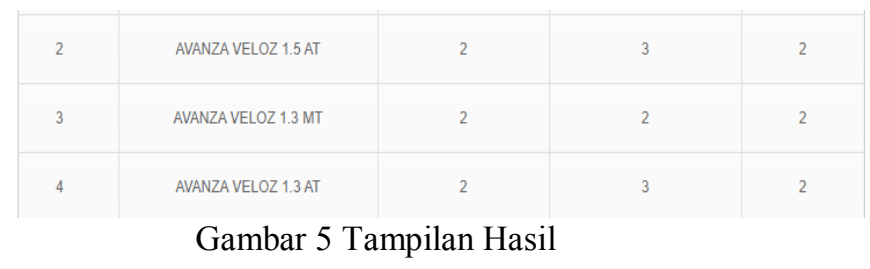

Tampilan Hasil Pembagian Kriteria 


\begin{tabular}{|l|l|l|l|l|}
\hline 2 & AVANZAVELOZ 1.5AT & 0.6666666666667 & 0.75 & 0.5 \\
\hline 3 & AVANZAVELOZ1.3MT & 0.66666666666667 & 0.5 & 0.5 \\
\hline 4 & AVANZAVELOZ 1.3AT & 0.66666666666667 & 0.75 & 0.5 \\
\hline
\end{tabular}

Gambar 6 Tampilan Hasil

\section{Hasil Hitungan Normalisasi Persamaan 1 Pada Sistem}

\begin{tabular}{|c|c|c|c|c|}
\hline ? & AANZA VELOZZ1.5AT & 0 & 1 & 0 \\
\hline 3 & AMANZAVELOZZ1.3NT & 0 & 0 & 0 \\
\hline 4 & AVANZAVELOZZ1.3AT & 0 & 1 & 0 \\
\hline
\end{tabular}

Gambar 7 Tampilan Hasil

Hasil Urutan Pada Sistem

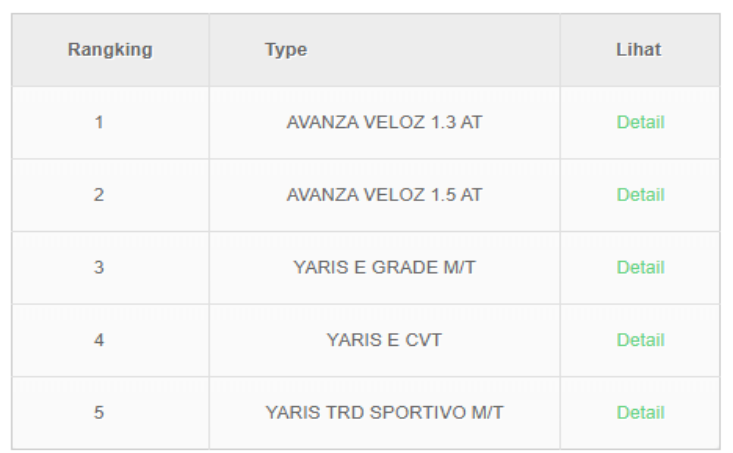

Gambar 8 Tampilan Hasil

Hasil perangkingan diperoleh dengan nilai akhir pada $\mathrm{A} 1=25, \mathrm{~A} 2=0$,dan $\mathrm{A} 3=25$ maka rekomendasi yang diperoleh dengan nilai tertinggi dan terbesar ada pada A3, tapi jika nilainya sama maka akan dilihat dari harga yang paling murah maka alternatif $\mathrm{A} 3$ adalah alternatif yang terpilih sebagai pembelian mobil baru.

\section{KESIMPULAN}

Berdasarkan hasil pembahasan pada bab-bab sebelumnya, maka dapat di tarik kesimpulan sebagai berikut:

1. Sistem pendukung keputusan pembelian mobil baru dapat dibuat dengan menggunakan bahasa pemograman seperti HTML, PHP, dan CSS. Kriteria yang dipakai dalam pembelian mobil baru yaitu: jumlah kursi yang memiliki 3 subkriteria di antaranya banyak jumlah kursi yang ada pada mobil, kapasitas mesin yang memiliki 4 subkriteria di antaranya rentang kapasitas mesin pada mobil dan Harga Mobil yang memiliki 2 subkriteria diantaranya harga yang ada pada mobil

2. Metode pengembangan sistem yang digunakan dalam aplikasi sistem pendukung keputusan pembelian mobil yaitu prototype, dengan perancanagn sistem yang dibuat yaitu Use Cse, Activity Diagram, Sequence Diagram, Entity Relationship Diagram (ERD), dan desaininterfaces.

3. Hasil perhitungan metode MAUT dengan nilai bobot pada mobil avanza veloz 1,5 $\mathrm{AT}=25$ dengan harga mobil 227.000.000, mobil avanza veloz 1,3 $\mathrm{MT}=0$ dengan harga mobil 239.000.000, dan mobil avanza veloz 1,3 AT=25 dengan harga mobil 220.000.000. Pada pengujian dengan mengimplementasikan metode MAUT yang dilakukan pada bab 4 menghasilkan nilai tertinggi sampai nilai terendah

4. Hasil pengujian sistem dengan menggunakan metode pengujian sistem whiteboxtelah berhasil dilakukan. Dimana dengan melakukan pengujian pada setiap path dalam 16 kali kali pengujianHasil dari implementasi telah sesuai denganperancangan dan semua modul program telah berfungsi dengan 
baik. Yaitu dirancang mulai dengan perancangan tampilan/flowchart, desain interfaces, sampai tahap pengkodean dan pengujian. Pengujian menunjukkan bahwa sistem informasi ini berjalan sesuai dengan yang diharapkan, dan tidak terjadi kesalahan logika.

\section{Saran}

Dalam perancangan dan pembangunan sistem pendukung keputusan ini, diharapkan aplikasi ini agar dapat:

1. Diharapkan aplikasi ini dapat dikembangkan, salah satunya dengan menambahkan kriteria mobil lebih lengkap dan terperinci lagi agar hasil yang didapatkan juga bisa sangat baik dalam penelitian ini

2. Menggunakan metode perhitungan yang berbeda untuk membandingkan hasilnya karena semua metode memiliki kekurangan dan kelebihan masingmasing.

3. Perlu adanya kriteria tambahan dalam proses rekomendasi mobil, karena semakin banyak kriteria maka proses penilaian akan semakin baik hasilnya.

4. Diharapkan dapat membandingkan metode yang dipakai pada penelitian ini dengan metode-metode SPK yang lain.

\section{DAFTAR PUSTAKA}

[1] Afriany, J., Ratna, L., Br, S., Julianty, I., \& Nainggolan, E. L. (2018). Penerapan MOORA Untuk Mendukung Efektifitas Keputusan Manajemen Dalam Penentuan Lokasi SPBU, 5(2), 161-166.

[2] Binarso, Y. A., Sarwoko, E. A., \& Bahtiar, N. (2012). Pembangunan sistem informasi alumni berbasis web pada program studi teknik informatika universitas diponegoro. Journal of Information and Technology, 1(1), 7284.
[3] Chamid, A. A. (2016). Penerapan Metode Topsis Untuk Menentukan Prioritas Kondisi Rumah, 7(2), 537544.

[4] Darmawan, A. S. (2012). Pemilihan Beasiswa Bagi Mahasiswa Stmik Widya Pratama Dengan Metode Profile Matching, (1), 1-5.

[5] Eniyati, S. (2011). Perancangan Sistem Pendukung Pengambilan Keputusan untuk Penerimaan Beasiswa dengan Metode SAW (Simple Additive Weighting), 16(2), 171-177.

[6] Februariyanti, H., \& Zuliarso, E. (2012). Rancang Bangun Sistem Perpustakaan untuk Jurnal Elektronik, 17(2), 124-132.

[7] Firman, A. (2016). Sistem Informasi Perpustakaan Online Berbasis Web.

[8] Halim, C., \& N, N. T. (2018). Prototype M-Culture Kota Solo, 4(55).

[9] Handayani, T. (2012). Penerapan Sistem Pendukung Keputusan Untuk Seleksi Mahasiswa Berprestasi Menggunakan Metode Ahp. Jurnal Transformatika, $9(2), \quad 79$. https://doi.org/10.26623/' sformatik a.v9i2.61

[10] Haviluddin. (2011). Memahami Penggunaan UML ( Unified Modelling Language). Memahami Penggunaan UML (Unified Modelling Language), 6(1), 1-15. https://doi.org/10.1017/CBO97811074 15324.004

[11] Hendini, A. (2016). Pemodelan UML Sistem Informasi Monitoring Penjualan dan Stok Barang (Studi Kasus: Distro Zhezha Pontianak), IV(2), 107-116.

[12] Imandasari, T., Wanto, A., \& Windarto, A. P. (2018). Analisis Pengambilan Keputusan Dalam Menentukan Mahasiswa PKL Menggunakan Metode PROMETHEE, 5(3), 234-239.

[13] Kurniawan, T. A. (2018). Pemodelan Use Case (UML): Evaluasi Terhadap beberapa Kesalahan dalam Praktik. 
Jurnal Teknologi Informasi Dan Ilmu

Komputer, $5(1)$

77.

https://doi.org/10.25126/jtiik.2018516 10

[14] Ladjamudin, A. Bin. (2005). Analisis Dan Desain Sistem Informasi. Graha Ilmu.

[15] Lumentra, S., Hermawan, J. T., \& Noviana, E. F. (2018). Analisis dan Perancangan Aplikasi Mobile Bisapinjam. Retrieved from http://eprints.polsri.ac.id/1082/3/BAB II .pdf

[16] Marlinda, L. (2016). Sistem Pendukung Keputusan Pemilihan Tempat Wisata Yogyakarta Menggunakan Metode ELimination Et Choix Traduisant La RealitA (ELECTRE), (November), 1-7.

[17] Nasibu, I. Z. (2009). Penerapan Metode AHP Dalam Sistem Pendukung Keputusan Penempatan Karyawan Menggunakan Aplikasi Expert Choice.

[18] Nurjannah, N., Arifin, Z., \& Khairina, D. M. (2015). Sistem Pendukung Keputusan Pembelian Sepeda Motor Dengan Metode Weighted Product, 10(2), 2-6.

[19] Mustaqbal, M. S., Firdaus, R. F., \& Rahmadi, H. (2015). Pengujian Aplikasi Menggunakan Black Box Testing Boundary Value Analysis (Studi Kasus: Aplikasi Prediksi Kelulusan SNMPTN). Jurnal Ilmiah Teknologi Informasi Terapan, 1(3), 31-36. Retrieved from http://jitter.widyatama.ac.id/index.php/ jitter/article/view/70

[20] Pujihastuti, I. (2010). Prinsip Penulisan Kuesioner Penelitian. Jurnal Agribisnis Dan Pengembangan Wilayah, 2(1), 43-56.

[21] Rakasiwi, S. (2013). Perangkat Lunak Bantu Sistem Penentuan Prestasi Karyawan PT. Telkom Divre IV Semarang. EBISNIS, 6(2), 11-18.

[22] Ramadiani, R., \& Rahmah, A. (2018). Sistem keputusan pemilihan tenaga kesehatan teladan menggunakan metode Multi-Attribute Utility Theory. Register: Jurnal Ilmiah Teknologi Sistem Informasi, 5(1), 1. https://doi.org/10.26594/register.v5i1. 1273

[23] Rini, N. (2010). Sistem Informasi Penjualan Barang Toko Sumber Urip. Teknik Informatika Fakultas Matematika Dan Ilmu Pengetahuan Alam Universitas Sebelas Maret.

[24] Santoso, L. W. (2013). Pelatihan Microsoft VISIO 2010 Profesional, 143.

[25] Shi, M. (2010). Software Functional Testing from the Perspective of Business Practice, 3(4), 49-52.

[26] Sutopo, P., Cahyadi, D., \& Arifin, Z. (2016). Sistem Informasi Eksekutif Sebaran PenjualanKendaraan Bermotor Roda 2 di Kalimantan Timur Berbasis Web. Informatika Mulawarman: Jurnal Ilmiah Ilmu Komputer, $\quad 11(1), \quad 23$. https://doi.org/10.30872/jim.v11i1.199

[27] Syahputra, T., Yetri, M., \& Armaya, S. D. (2017). Sistem Pengambilan Keputusan Dalam Menentukan Kualitas Pemasukan Pangan Segar Metode Smart, IV(1), 7-13.

[28] Syofian, S., Setiyaningsih, T., \& Syamsiah, N. (2015). Otomatisasi metode penelitian skala likert berbasis $w e b$. Tinf-023, (November), 1-8.

[29] Windarto, A. P. (2017). Implementasi Metode Topsis Dan Saw Dalam Memberikan Reward Pelanggan. Klik - Kumpulan Jurnal Ilmu Komputer, 4(1), 88. https://doi.org/10.20527/klik.v4i1.73 